\title{
Risks and vulnerabilities of youth towards STIs and HIV infection; a cross sectional study among youth attending 'Youth Corps Centres' in Western Province of Sri Lanka
}

\author{
P S K Batagalla, Ariyaratne Manathunge
}

\begin{abstract}
Introduction: Youth is the period where individuals transform from dependent childhood to independent adults. The incidence of Sexually Transmitted Infections (STI) and HIV among youth in Sri Lanka, is rising.

Objective: To assess the risk behaviours and vulnerabilities towards Sexually Transmitted Infections and HIV among youth attending youth corps centres in the Western province of Sri Lanka.

Method: A descriptive cross sectional study was carried out using a self-administered questionnaire among the trainees attached to youth corps centres (YCC) in Western province from October 2019 to February 2020.

Results: Youth attached to YCC were educated and were from poor economic background. A fair proportion had a good level of knowledge on STIs and HIV. Knowledge was positively associated with age, educational level and the wealth quintile. There is a significant difference of knowledge across ethnic and religious categories. Only $15.5 \%$ reported being sexually active and the majority of them (79.2\%) were having multiple partners. Only $41 \%$ agreed that they would use condoms in the future. Sense of invulnerability, peer pressure, embarrassment to buy were the main reasons for not using a condom. Major source of SRH information was the internet and the available SRH services are underutilized, mainly due to unawareness.
\end{abstract}

Conclusions: Knowledge on STIs and HIV among these youth was satisfactory and a minority were sexually active. Risk behaviours were higher and access to available SRH services were poor.

Key words: Youth, Sri Lanka, Sexually Transmitted Infections, HIV

Authors: corresponding author; ${ }^{1}$ Dr P.S.K. Batagalla, MBBS, PgDVen, MD, Consultant Venereologist, District General Hospital, Vavuniya. Email: pskbatagalla@yahool.com, (1D https://orcid.org/0000-0002-4629-1240 ${ }^{2}$ Dr Ariyaratne Manathunge, MBBS, MSC, MD, Consultant Venereologist, National STD/AIDS Control Programme, Colombo. Email: ariyaratne1@gmail.com, (D) https://orcid.org/0000-0001-9514-9227

Acknowledgement: All the participants in the study, and all who helped in this study Conflict of interest: Authors claim no conflicts of interest, Funding: not funded, Originality: This is an original work which has been not published anywhere else, presented at $25^{\text {th }}$ Annual Scientific Sessions of Sri Lanka College of Sexual Health and HIV medicine 2020, Submitted: 


\section{Full article}

\section{Introduction}

"Youth" is best understood as a period of transition from the dependence of childhood to adulthood's independence and awareness of inter-dependence as members of a community. There are many reasons for the growing attention to the health of youth. Firstly, about $16 \%$ of a country's population is composed of youth. (1) Secondly, the foundations laid during adolescence on education, skills and health will have impacts of social and economic development of a country. (2)

HIV disease continues to be a serious health issue for parts of the world and, about 38 million people are living with HIV around the world in 2019. (3) Young people aged $15-24$ years accounted for more than $30 \%$ of new HIV infections worldwide. (4) Even though Sri Lanka is currently experiencing a low level HIV epidemic, it is noted that there is a rising trend of HIV incidence among youth in Sri Lanka during recent years. (5)

Issues related to sexual health among youth have gained a high priority in Sri Lanka, because of the expansion of media, information technology, education, urbanization and equal opportunities for social mixing among boys and girls. However, the issues related to reproductive and sexual health are not very well addressed within the context of the Sri Lankan healthcare system and most of the available services such as family planning services are targeted towards married people.

National Youth Corps provide vocational training to the out of school youth in Sri Lanka through a network of centres situated throughout the island. As the out of school youth recruited after their ordinary level and advanced level examinations, it would be appropriate facility to catch these fresh youth to assess their vulnerability towards STIs and HIV infection.

\section{Objectives:}

To assess. The. risk behaviours and vulnerabilities towards sexually transmitted infections (STIs) and HIV among youth attending youth corps centres in the Western province.

\section{Methods}

A descriptive cross sectional study was carried out in the five YCC located in Western province, namely; Attanagalla, Bulathsinhala, Divulapitiya, Katunayake and Yakkala from October 2019 to February 2020.

Out of 541 youth attached to above centres, 404 were recruited for the study through proportionate random sampling using a random number table. Trainees who had any sort of SRH training during preceding 6 months were excluded.

A self-administered questionnaire was used for data collection. The questionnaire assessed their demographic details, knowledge on STIs and HIV, risk behaviours and sources of SRH information. The principal investigator was available for clarifications during the data collection process. Data were analysed using SPSS 20. To assess the knowledge, a knowledge score was designed separately for STIs and HIV. A score of 10 or more out of 15 was regarded as good knowledge. Knowledge scores were compared with their demographic factors. Quantitative data were analysed with regard to measures of central tendency and dispersion whilst qualitative data were analysed with regard to proportions.

\section{Results}

\section{Socio-demographic characteristics.}

More than half of the sample $(55 \%)$ was boys and the mean age was 17.9 years. Most of the sample composed of Sinhalese Buddhists. Their level of education is quite higher, $97.5 \%$ educated at least up to ordinary level. Ninety five percent of them were living with parents and a three quarter is from lower economic background having a monthly family income less than Rs. 50,000.

The socio-demographic profile is shown in table 1. 
Table 1: Socio-demographic profile of the study sample

\begin{tabular}{llrr}
\hline \multirow{2}{*}{$\begin{array}{l}\text { Socio-demographic } \\
\text { characteristic }\end{array}$} & No. & $\%$ \\
\hline \multirow{2}{*}{ Gender } & Male & 222 & 55 \\
\cline { 2 - 4 } & Female & 182 & 45 \\
\hline \multirow{2}{*}{ Age } & $<18$ yrs & 212 & 52.5 \\
\cline { 2 - 4 } & $>18$ yrs & 192 & 47.5 \\
\hline Level of & Dropped out $<$ & 10 & 2.5 \\
education & Grade10 & & \\
\cline { 2 - 4 } & Completed O/L & 286 & 70.8 \\
\cline { 2 - 4 } & Completed A/L & 108 & 26.7 \\
\hline Monthly & $<50,000$ & 310 & 76.7 \\
\cline { 2 - 4 } family & $>50,001$ & 88 & 21.8 \\
\cline { 2 - 4 } income(Rs) & Missing & 6 & 1.5 \\
\hline Ethnicity & Sinhalese & 368 & 91.1 \\
\cline { 2 - 4 } & Tamils & 14 & 3.5 \\
\cline { 2 - 4 } & Muslims & 20 & 5.0 \\
\cline { 2 - 4 } & Other & 2 & 0.5 \\
\hline Religion & Buddhists & 608 & 76.2 \\
\cline { 2 - 4 } & Hindu & 1.5 \\
\cline { 2 - 4 } & Islam & 6.9 \\
\cline { 2 - 4 } & Catholic & 1.5 \\
\cline { 2 - 4 } & Other & & 14.9 \\
\hline
\end{tabular}

\section{Knowledge on STIs and HIV}

To assess the level of knowledge, a "knowledge score" was designed separately for STIs and HIV. Cut off point for good knowledge was considered as 10 or more out of 15 . These scores were compared with other sociodemographic characteristics. Of the sample $33.9 \%$ had a sound knowledge on STIs whilst, $33.3 \%$ had a good knowledge on HIV. Age, level of education and wealth quintile were positively associated with both HIV and STI knowledge scores. However, there is a significant difference of knowledge scores across the ethnic and religious categories.

Graph 1: Association of knowledge with age

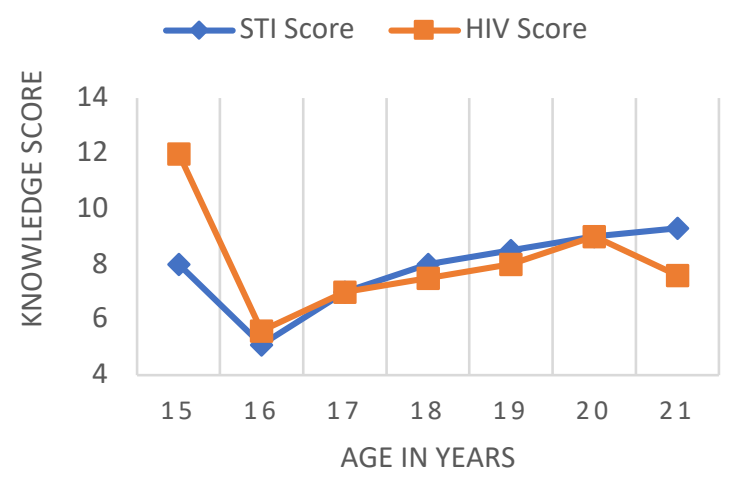

Graph 2: Association of knowledge with wealth quintile

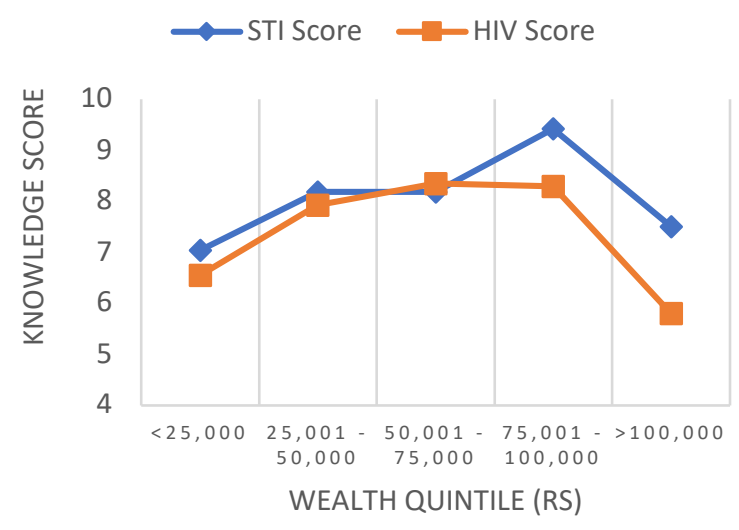

\section{Risk Behaviours}

Only $15.5 \%$ of the participants reported having sexual exposure ever ( $n=64)$. Among them, $90 \%$ were boys. About $68.8 \%$ of them were between 16 to 20 years of age at their first sexual exposure. The majority $(53.1 \%)$ had sex with their girl or boyfriend. Of the respondents, $12.6 \%$ reported having first sex with a paid or an unknown partner. Interestingly, 40 out of 64 sexually active youth continued to have sex (62.5\%) and $43 \%$ had multiple partners (Graph 3).Among sexually active youth, $24 \%$ had ever engaged in a homosexual relationship.

Graph 3: Type of partner at first intercourse

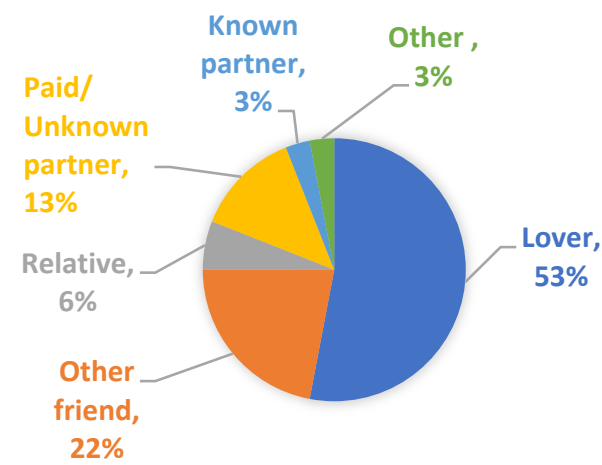

Majority have heard of condoms (286, 70.8\%). Of the sexually active youth, $34.3 \%$ have ever used a condom. Fair proportion knew where they can buy a condom still, $32.6 \%$ had no idea where to go for a condom. Forty one percent said that they would use a condom in the future and the main reasons were to protect from STIs (78.1\%), as a contraceptive (63.6\%) and as per the partners need. Alarmingly, $59 \%$ did not wanted to use a condom in the future. 
This is mainly due to the sense of invulnerability towards STIs, embarrassment to buy and not knowing how to use them.

\section{Sources of SRH information}

Majority, $80.6 \%$ agreed that SRH knowledge is important for them. Commonest mode of SRH information was internet (76\%). Health care workers (68.5\%), electronic media $(62.5 \%)$ and teachers $(68.3 \%)$ were the other sources of SRH information. Unfortunately, $80 \%$ did not know about "youth friendly clinics" in government hospitals.

Out of 404 participants, $65.3 \%$ said that the pornographic material available in the internet and $64.6 \%$ have facilities to access them. Most common method of watching internet porn is through mobile phone followed by laptop/desktop computer and tablets. Ten percent of these youth said that they access these on daily basis. Further, almost one third of the sample (30\%) wanted to try them out in real life.

Exploring the effective modes of SRH information, lectures (93.6\%), digital media $(74.8 \%)$, social media $(71.8 \%)$, and parents $(67.8 \%)$ were the preferred sources of information and were the most effective ways to disseminate information according to their wish.

Casting about the barriers to service access, $83.7 \%$ reported unawareness was the most proximal factor for under-utilization of available services. Fear of stigma (30.6\%), not having enough confidence to attend services (24.7\%) and inconvenient opening times (20\%) were other barriers.

\section{Discussion}

The education level of the study participants was higher compared to the general population of the Western province, as these youth were recruited to YCC after their ordinary level exams. (6)

According to the study findings, $33.9 \%$ had a sound knowledge on STIs and $33.3 \%$ had a good knowledge on HIV. Even though these scores show a poor knowledge, they are comparable to the HIV/STI knowledge of youth in the regional countries. (7)(8)
Comparison of knowledge scores with gender, did not reveal any difference. Educational attainment, age and monthly family income were positively associated with level of knowledge. This finding can be expected as with rising age and level of education may have expose them to more information on SRH. Higher family income also would have helped them to access more material on SRH. Comparison of knowledge scores with ethnicity and religious categories showed a significant difference. This implies, there can be ethnic or religious influence on accessing SRH information by youth and, it would be a timely topic for future research.

Only a minority was sexually active, but risky behaviours such as having multiple partners and not using condoms were fairly higher, exposing them to sexually transmitted infections. Though $70 \%$ of them have heard of condoms, use of condoms was fairly poor among sexually active youth. This again increases the chances of catching infections as a considerable proportion had multiple sexual partners. Even though a high proportion have heard of condoms, majority would not use a condom in the future mainly due to sense of invulnerability towards STIs.

A fair proportion believe SRH information is important for them, which is good. Internet being the commonest mode of access to SRH information, it is mandatory to make accurate and updated information available in the internet and make them aware of the reliable web sites. Going beyond the limits, it is high time to capitalize on social media to promote sexual health among youth, and capacitate and engage youth in designing and development of novel methods to reach them.

Unawareness being the most proximal reason for under-utilization of available services, it is high time to canvas SRH services among youth and make them realize that there is no stigma at service delivery points.

\section{Conclusions}

A fair proportion of youth attending YCC in the Western province have a good knowledge on STIs and HIV. Among the minority of sexually active youth, risky sexual behaviours were common. Their main sources of SRH 
information was internet, health care workers and electronic media. Their preferred sources of SRH information were lectures, digital media and social media rather than posters and leaflets. Their access to existing SRH services were poor, mainly due to lack of awareness.

\section{References}

1. United Nations. International Youth Day. [Online].; 2019 [cited 2020 July 21. Available from: https://www.un.org/development/desa/youth/wpcontent/uploads/sites/21/2019/08/WYP2019_10Key-Messages_GZ_8AUG19.pdf.

2. Sawyer SM ARea. Adolescence: a foundation for future health. The Lancet. 2012;(379): 1630-1640.

3. UNAIDS.org. Global HIV \& AIDS Statistics - 2020 factsheet. [Online].; 2020 [cited 2020 July 19. Available from: https://www.unaids.org/en/resources/fact-sheet.

4. World Health Organization. HIV and youth. [Online].; 2020 [cited 2020 June 21. Available from: https://www.who.int/maternal_child_adolescent/t opics/adolescence/hiv/en/.

5. National STD/AIDS Control Programme. Annual Report 2018. [Online].; 2019 [cited 2020 April 26. Available from: http://www.aidscontrol.gov.lk/index.php?option=c om_content\&view=article\&id=19\&ltemid=139\&lan $\mathrm{g}=\mathrm{en}$.

6. Department of census and statitstics, Sri Lanka. Household income and expenditure survey. [Online]. Colombo; 2016 [cited 2020 April 25. Available from: http://www.statistics.gov.Ik/HIES/HIES2016/HIES20 16_FinalReport.pdf.

7. International Institute of Population Sciences. National family health survey - 4. [Online]. Mumbai, India; 2017 [cited 2020 April 25. Available from: : http://rchiips.org/nfhs/NFHS-4Reports/India.pdf.

8. Thapa K CS. Medcraveonline.com. [Online].; 2018 [cited 2020 March 19. Available from: https://medcraveonline.com/MOJPH/MOJPH-0700213.pdf. 